\title{
Extreme Makeover Reference Edition: Restructuring Reference Services at the Robert W. Woodruff Library, Atlanta University Center
}

\section{Kimberley L. Bugg \& Rosaline Y. Odom}

To cite this article: Kimberley L. Bugg \& Rosaline Y. Odom (2009) Extreme Makeover Reference Edition: Restructuring Reference Services at the Robert W. Woodruff Library, Atlanta University Center, The Reference Librarian, 50:2, 193-204, DOI: 10.1080/02763870902755932

To link to this article: http://dx.doi.org/10.1080/02763870902755932

曲 Published online: 31 Mar 2009.

Submit your article to this journal $\pi$

山ll Article views: 447

Q View related articles $\sqsubset$

Citing articles: 7 View citing articles $\square$ 


\title{
Extreme Makeover Reference Edition: Restructuring Reference Services at the Robert W. Woodruff Library, Atlanta University Center
}

\author{
KIMBERLEY L. BUGG and ROSALINE Y. ODOM \\ Robert W. Woodruff Library, Atlanta University Center, Atlanta, GA
}

\begin{abstract}
The Robert W. Woodruff Library, Atlanta University Center, recently restructured its system for information service delivery by moving from the traditional one-desk model to a dual component model that is delivered from two service points in close proximity. Under the former system, services were solely delivered by reference librarians. The new system offers the same array of information services provided by a combination of librarians and library support staff who have received special training. The observed outcomes have been a higher quality of customer service delivery, an increased use of research consultation services, a more informed and engaged library staff, and increased opportunities for reference librarians to make campus visits. This article outlines the entire process from conception to implementation, including staff training requirements, statistical data, and future implications.
\end{abstract}

KEYWORDS reference, reference services, information \& research services

\section{INTRODUCTION}

The logistics surrounding the delivery of reference services in academic libraries-from where and by whom-are a long-standing point of contention among academic libraries that has spanned decades (Fritch and

Address correspondence to Kimberley L. Bugg, Reference Librarian and Subject Liaison, the Robert W. Woodruff Library, Atlanta University Center, 111 James P. Brawley Drive, Atlanta, GA 30314. E-mail: kbugg@auctr.edu 
Mandernack 2001; Harrelson 1974; Kleiner 1968). Reference service delivery has evolved from a single desk to multi-tiered service points to onsite delivery at remote locations to the electronic delivery reference services at the point of need (Arendt and Taylor 2006; Radcliff 1998; Sonntag and Palsson 2007; Whitson 1995). Regardless of the delivery model used, reference services represent one of the most important criteria used by academic library stakeholders (the faculty, students, staff, and administrators) to measure the effectiveness of the library. As academic libraries strive to meet the information needs of 21st century library users, so continues the struggle to resolve the reference dilemma of how to reduce the amount reference librarians' time that is consumed in answering directional and other non-reference questions at the reference desk (Sonntag and Palsson 2007).

\section{LITERATURE REVIEW}

The push to redefine models for reference service delivery is a direct result of an array of circumstances that impact libraries in general. The idea of using a tiered service delivery (information service desk separate from reference services) actually dates back more than 40 years. Jane Kleiner conducted the first assessment of use of information desks in 1968 and Larry Harrelson conducted a subsequent study in 1974 (Mosely 2007). Whitson (1995) attributed the observed changes to three trends: budgetary stringency, the call for accountability, and the rapid increase in what a librarian needs to know to provide competent reference service. Whitson provided a comprehensive discussion of the advantages and disadvantages of traditional versus differentiated reference service delivery. Radcliff (1998) suggested that the increased use of tiered reference services in academic libraries has occurred in an effort to increase efficiencies, maximize staff resources, and better meet the diverse needs of users. The question now is: Do information desks in academic libraries represent a concept whose time has come? The answer depends on the type of information environment in which they are located and the characteristics of the library users served.

In 1998, Massey-Burzio published an article that called attention to the ongoing decline in reference desk user statistics, noting that Johns Hopkins University recorded a decline in use at all service points, including its Research Center. She predicted that the trend toward less face-to-face interactions and an increased use of remote services would continue. MasseyBurzio (1998) also cautioned librarians about the need to spend more time building and promoting other services, such as instruction, web portals, and accessing full-text journals, and less time waiting for users to come to the reference desk for help.

Recognizing the emerging trends, Massey-Burzio went on to conduct a study about the "quality and effectiveness" of reference, with a focus on 
patron needs and preferences. Six focus groups composed of six library users each (undergraduate students, graduate students, continuing studies students, and faculty) were asked to describe their experiences in retrieving information, learning how to use the library, thoughts about library staff, skill level with library use, and the value of librarians. One of the most significant findings revealed that library patrons dislike having to ask questions. Most library users felt that they knew how to find information pretty well, having learned to use the library through friends and experimentation. The responses generated discussion about the following: "Should reference librarians work on developing a savvier library user that understands how to use the library efficiently and effectively?" This would support a move to transform the current service delivery model from a reference services focus to liaison and instruction services (Massey-Burzio 1998).

Massey-Burzio (1992) conducted the same type of transformation at Brandeis University. In response to increasing responsibilities of the reference librarians, changing library priorities, shrinking budgets, staffing problems, and facilities redesign, the university opted to discontinue providing information services at a "reference desk" and sought to deliver services from two service points: the Information Desk and the Research Consultation Service Office. Graduate students staffed the Information Desk and librarians staffed the Research Consultation Service Office. The design allowed general information questions to be answered at the Information Desk and more involved questions to be referred to librarians.

It was determined that the new mode of delivery increased the quality of service. Patrons and staff both reported feeling less hurried during transactions. Librarians expressed an increased sense of job satisfaction. The Brandeis model also provided specific guidelines for operating the Information Desk. For example, questions that required more than 3 minutes for the Information Desk staff to handle were referred to the librarians. The Research Consultation Service Office provided one-on-one assistance, similar to the type of interactions students experienced in their professor's office. People at Brandeis were pleased with the personal, high quality service received in the Research Consultation Service Office, resulting in an improved interaction quality (Massey-Burzio 1992).

During the March 3, 2006, Columbia Reference Symposium, Jennifer Harter presented Massachusetts Institute of Technology Hayden Library's combined Service Desk. In her presentation, she detailed how they combined five libraries into one library. The transformation included a single service desk with tiered information service provided by different levels of professionals and provided a "just in time" customer service staffing model rather than a "just in case" model. The model provided more time for staff to be away from the desk working on other projects and more self-sufficiency for library patrons. While developing this model, they assembled a list of 100 competencies that every staff member working the single service point 
would have to possess to provide a basic level of service. Under this single service point model, reference, circulation, and course reserves were all centrally located at a combined service point. Persons staffing the service point included two circulation staff members, one member of the reference staff, and one "on-call" staff person. Duties are rotated among 30 staff members.

During the pilot and implementation phases, several challenges arose, including combining the cultures of different departments to form one cohesive team, patrons complaining about location changes, and the new division of labor. In an effort to resolve these issues, the library initiated more training, including individual training for new hires, on-the-job-training, and a customer service-training program. Overall, both the pilot and implementation phases were successful. The staff recognized further opportunities for better referrals, improved circulation transactions, and better signage (Harter 2006).

Numerous library reference service models were reviewed by a team of reference librarians. Most proved to be helpful in structuring the Woodruff Library's new reference service delivery model. Each university offered either one-on-one interactions between the librarian and the student or tiered levels of service (Lipow 2003). The library models reviewed by the team were from Simon Fraser University (Wong and O'Shea 2004), the University of Florida and Eastern University (Cook 2006), and the University of California-Berkeley (Whitson 1995). Lipow's (2003) article on point of need reference service outlined the various components required for libraries opting to initiate tiered information services.

\section{ABOUT OUR LIBRARY}

Constructed in 1982, the Robert W. Woodruff Library is named in honor of Robert Winship Woodruff, former CEO of the Coca Cola Company. The library was designed to serve the instructional, informational, and research needs for member institutions of the Atlanta University Center Consortium, the world's largest and oldest consortium of Historically Black Colleges and Universities. The institutions that comprise the Atlanta University Center Consortium are Clark Atlanta University, the Interdenominational Theological Center, Morehouse College, Morehouse School of Medicine, and Spelman College.

The Robert W. Woodruff Library is open 94.5 hours weekly and mediated services are offered 92 hours weekly. The library is currently undergoing a period of transformation and recently restructured its system for information service delivery by moving from the traditional one desk model to a dual component model that is delivered from two service points that are in close proximity. 


\section{RATIONALE FOR CHANGE}

Prior to the transition to a two-desk information service delivery model at Robert W. Woodruff Library, much of the reference librarians' time was spent at the Reference Desk answering directional and general questions, distributing headphones, assigning group study rooms, or troubleshooting printer and copier issues. Library users who required assistance with assignments or research were frequently forced to wait in long lines while those other transactions were completed. Reference librarians spent approximately half of the 35-hour work week at the Reference Desk. The librarians often found it difficult to schedule time for outreach activities on the campuses of member institutions while also conducting instruction sessions and completing other projects. Librarians often complained that they were not able to provide in-depth research services to those library users who sought that at the Reference Desk because of the amount of time they spent on other types of transactions.

Figure 1 displays Reference Desk statistics from 2006. Most interactions involved directional questions and ready reference checkouts. Following a meeting with the Loretta Parham, CEO and Director of the library, a review of the literature was conducted. Subsequent to a series of meetings with all departments involved in public service delivery, a proposal was developed along with an implementation plan that detailed the steps required for transforming information service delivery at the Woodruff Library to a two-desk model.

The proposal outlined all of the resources required to successfully perform the plan for library staff and administrators. The first desk is an Information Services Desk located at a shared public service desk that also houses Circulation Services and course reserves. The second component is the Research Consultation Center (RCC), located within close proximity to the Information Services Desk, that provides a quieter site for reference

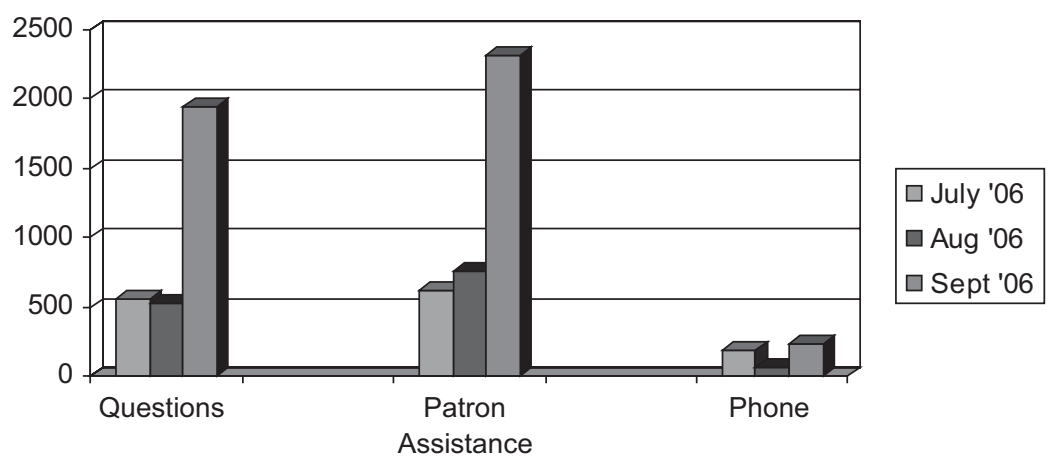

FIGURE 1 Reference desk statistics - Summer 2006. 
librarians to provide one-on-one assistance to library users who requir help with assignments or research projects. Library users have the option of receiving help by making an appointment or visiting the RRC as walk-ins at the point of need.

Creating the Information Services Desk required the reference librarians and other library staff to take a candid look at the array of service transactions usually delivered from the Reference Desk and determine which services could effectively be delivered by non-librarians. The decision was reached through a series of discussions by a group of library staff with representatives from all library units, including Circulation Services, Access and Technical Services, Facilities Management, Security, Information Technology, and Information and Research Services. Discussion topics included scheduling, training, layout of furniture and equipment, and proposed services. Once the proposal was accepted, the pilot program was implemented. The new service delivery model was initiated during the summer session to allow sufficient time for revisions to the mode of operation prior to the start of the fall semester.

\section{Staffing}

The Information Services Desk is staffed during normal operating hours in 2-hour shifts by a combination of librarians, library support staff, and student assistants (Table 1 represents the schedule for the Information Services Desk). A decision was made to select workers from all library departments to staff the Information Services Desk.

Cross-training was provided to insure consistent service delivery. This fostered a "team spirit" atmosphere throughout the library and allowed a variety of library staff to become actively involved in customer service delivery. Each 2-hour shift at the Information Services Desk is normally staffed by a member of the library staff and a student assistant. The student assistant and Information Services Desk staff work together to ensure that someone is available to help users at the desk and on the floor as needed. Student

TABLE 1 Information Services Desk Duty Roster

\begin{tabular}{lcccclll}
\hline Time & Monday & Tuesday & Wednesday & Thursday & Friday & Saturday & Sunday \\
\hline 8 a.m.-10 a.m. & IRS & GOV & GOV & GOV & ATS & Closed & Closed \\
10 a.m.-12 p.m. & ILL & ATS & ATS & ATS & CIR & Closed & Closed \\
12 p.m.-2 p.m. & CMC & ATS & IRS & CMC & CMC & IRS & IRS \\
2 p.m.-4 p.m. & IRS & ATS & SYS & ATS & ILL & IRS & IRS \\
4 p.m.-6 p.m. & GOV & ATS & ATS & ATS & CMC & IRS & IRS \\
6 p.m.-12 a.m. & IRS & IRS & IRS & IRS & Closed & Closed & IRS \\
\hline
\end{tabular}

Note. ATS $=$ Access \& Technical Services Staff; CIR = Circulation Services Staff; CMC = Curriculum Materials Center Staff; GOV = Government Documents Staff; ILL = Interlibrary Loan Staff; IRS = Information \& Research Services Staff; SYS = Systems Librarian. 
assistants are also responsible for roving the library to troubleshoot for potential printer or copier problems and to provide "just in time" services to library users at public workstations.

The RCC is staffed by 10 full-time reference librarians and 2 part-time reference librarians. The hours of operation are from 10 a.m.-10 p.m. Monday through Thursday; 10 a.m.-6 p.m. on Friday, and 12 p.m.-8 p.m. on Sunday. The hours were determined from an analysis of the past year's Reference Desk statistics, which indicated peak usage during the hours selected. Usage at other times was very low. Reference librarians are scheduled to work one of the following shifts: 10 a.m. -4 p.m., 4 p.m. -7 p.m., or 7 p.m. -10 p.m. (staffed by part-time reference librarians) during the week, and 12 p.m.-8 p.m. on Sundays. On Saturdays, library use is traditionally low and reference librarians work at the Information Services Desk, providing both information services and research assistance from a single service point desk. On Sundays, the librarian on duty works from the Information Services Desk until 4 p.m. On average, reference librarians work 1 weekday shift weekly and 1 weekend shift monthly (Table 2 provides a sample schedule for the RCC).

\section{Training}

All staff designated to operate the Information Services Desk participated in a series of training sessions that were conducted over the course of a week during a time when the library was closed to the public. The initial training covered various aspects of library operations and each trainee was provided with a manual as reinforcement for concepts covered during the sessions. The goal was to provide Information Services Desk staff with basic knowledge of library operations and the confidence to conduct. The training was also designed to facilitate the ability to recognize when to answer user questions and when to refer users to a reference librarian.

Four training modules were presented to the Information Services Desk staff. Module One-Information Desk was designed to provide the trainees

TABLE 2 Research Consultation Center (RRC) Duty Roster

\begin{tabular}{|c|c|c|c|c|}
\hline Day & $\begin{array}{l}\text { RCC day } \\
10 \text { a.m. }-4 \text { p.m. }\end{array}$ & $\begin{array}{l}\text { Lunch relief } \\
1 \text { p.m.-2 p.m. }\end{array}$ & $\begin{array}{l}\text { RCC evening } \\
4 \text { p.m. }-7 \text { p.m. }\end{array}$ & $\begin{array}{c}\text { RCC night } \\
7 \text { p.m. }-10 \text { p.m. }\end{array}$ \\
\hline Monday & LIB \#1 & LIB \#2 & LIB \#2 & PT LIB \#1 \\
\hline Tuesday & LIB \#3 & LIB \#4 & LIB \#4 & PT LIB \#2 \\
\hline Wednesday & LIB \#5 & LIB \#6 & LIB \#6 & PT LIB \#2 \\
\hline Thursday & LIB \#7 & LIB \#8 & LIB $\# 8$ & PT LIB \#1 \\
\hline Friday & $\begin{array}{l}\text { LIB } \# 9 \text { ) } \\
\qquad(10 \text { a.m. }-2 \text { p.m. })\end{array}$ & $\begin{array}{l}\text { LIB } \# 10 \\
\qquad(2 \text { p.m. }-6 \text { p.m. })\end{array}$ & Closed & Closed \\
\hline Saturday & Closed & Closed & Closed & Closed \\
\hline Sunday & Closed & Closed & $\begin{array}{l}\text { Rotating LIB } \\
\quad(4 \text { p.m. }-8 \text { p.m.) }\end{array}$ & Closed \\
\hline
\end{tabular}


with an overview of the philosophy behind the new service delivery model. It also covered relevant policies and procedures for answering telephones, circulating ready reference materials, making room reservations, providing general patron assistance, reporting problems with facilities and equipment, and handling emergency situations. Module Two-Information Services provided an overview of the library's print information resources along with mechanisms for accessing each type of information. Module Three-Circulation Services provided an overview of services primarily offered by Circulation staff, such as course reserves, book check outs and fines. Participants also received instruction on how to operate and troubleshoot library print stations, copiers, scanners, and bill changers. Module Four-Library Website provided an intense introduction to the library's electronic information resources and information about how library users can access information from remote locations. Participants were required to complete a short quiz at the end of each module presentation. After all modules were completed, workshop facilitators conducted review sessions to clarify points of confusion and to reinforce areas of weakness identified by quiz results. Recognizing that training would have to be continuous, a schedule of refresher courses was developed. New hires automatically receive one-on-one training. Each reference librarian was assigned to at least one Information Services Desk staff person to insure that each trainee had a "go to" person for advice about operations.

\section{Layout}

A series of informal meetings was conducted with the facilities coordinator and Information Technology staff, and a floor plan was developed for the Information Services Desk and RCC. Consideration was given to spacing, fire safety, the locations of internet connections and phone jacks, and the availability of furniture and equipment. The decision was made to use two unoccupied workstations at the existing Circulation Desk for the Information Services Desk. This area is near the main library entrance and already familiar to our library users. One workspace would be equipped for the Information Services Desk staff and another for a student assistant. Both workstations would have a computer and a telephone would be shared between the two. One computer would be formatted with an abbreviated circulation system for charging and discharging headphones and readying reference materials. Many services formerly offered at the Reference Desk would now be offered at the Information Services Desk, including interlibrary loan pick up (Figure 2).

An unoccupied cubicle behind the former Reference Desk was furnished to function as the RRC. The area is in close proximity to the Information Services Desk and adjacent to several of the library's public use computers. The floor plan includes two side-by-side desks that are each equipped with 


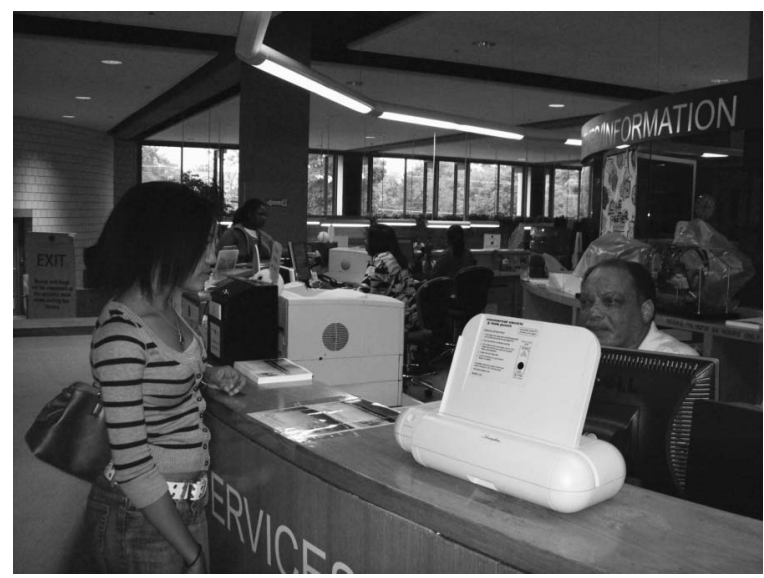

FIGURE 2 Information services desk.

computers (the second computer is for use by library users). The librarian's desk is equipped with a telephone for delivery of telephone reference services. Because librarians spend a significant portion of the work week in the RCC, an effort was made to provide materials and equipment to facilitate the completion of special projects and other assignments. Both desks offer comfortable seating, adequate lighting, and ample workspace. Other modifications that were deemed important for both service areas were updating signage, updating our website, and ensuring that subject librarians' business cards were available in both locations.

\section{Service Delivery}

Services offered at the former Reference Desk were divided between the Information Services Desk and the RCC. Directional questions, ready reference checkouts, room reservations, headphone checkouts, and interlibrary loan pick up were assigned to the Information Services Desk. Research questions, faculty requests, local university borrowing privileges, and any other questions requiring more than 3 minutes of service were designated as referrals for the RCC. For added service efficiency, Information Services Desk staff members were asked to make referrals to the RRC by calling the RCC and letting the librarian know that a library user requires assistance. The librarian then walked to the Information Services Desk to greet and escort the library user to the RCC (Figure 3). Librarians are required to complete a consultation sheet (detailing the interaction) after each consultation. These documents are used for statistical purposes and to help shape decisions about library instruction offerings. RCC librarians also responsible for providing telephone, e-mail, and instant messaging reference service. 


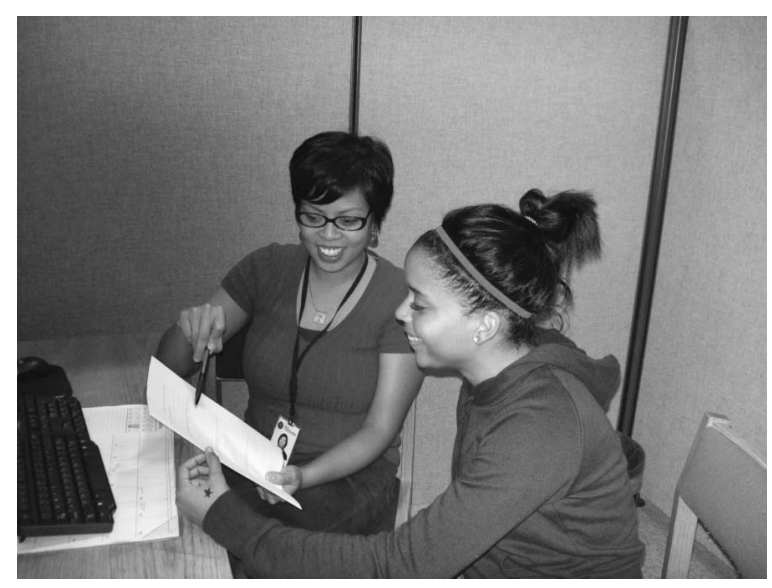

FIGURE 3 Research consultation center.

\section{Benefits of New System}

Since their inception, both the Information Services Desk and RCC have gained in popularity among library users. There has been a $+100 \%$ increase in request for research assistance. Some trends that have been observed since implementation are:

- The average RCC transaction is 28 minutes long. This is impressive because spending this amount of time with one library user was impossible at the reference desk;

- The RCC averages approximately 100 consultations per month;

- Peak RCC and Information Services Desk usage time is between 12 p.m. and 4 p.m.;

- Undergraduate students use the service more than any other user group;

- $53 \%$ of all RCC transactions are referred to a subject librarian;

- $25 \%$ of all RCC transactions result in an interlibrary loan request;

- $91 \%$ of all RCC transactions are Information Services Desk referrals;

- $8 \%$ of all RCC transactions are faculty referrals;

- $40 \%$ increase in question asked at the information desk over the reference desk; and

- One-stop shopping for library users in need of general information services (book check-out, course reserves, and room reservations)

Reference librarians have expressed a great deal of satisfaction with new system for the following reasons:

- Librarians are able to get out of the library and do more campus outreach;

- Less scheduling conflicts; 
- Increased opportunities to work on projects;

- More time for instruction;

- Students appear to approach the Information Desk more often when they see their peers (student assistants);

- Persons not originally slated to work the Information Desk have volunteered to be included in the rotation.

\section{Implications for the Future}

Currently, the Information Services Desk team meets once a semester. More frequent meetings might help build a more cohesive team and assist with desk operations because frequent communication is the best way to insure that everyone is delivering the same message. Refresher training workshops have been initiated and will occur at the end of each school session. Librarians who currently staff the RCC have begun a discussion about the need to add "Information Literacy Standards achieved" to the RCC statistical data sheet. This will help reference librarians assess the extent to which the Association of College and Research Libraries (ACRL) information literacy standards are being met during research consultations. Other aesthetic upgrades, such as dual computer monitors at the Information Services Desk, would be beneficial as well to improve point of need demonstrations for library users with general reference questions. An additional computer has been requested to accommodate periods during the semester (pre-midterms/pre-finals) when the RCC experiences a high volume of users.

\section{CONCLUSION}

The Robert W. Woodruff Library has made the transition from a traditional reference desk model where librarians sit behind the desk and wait for library users to overcome their apprehension and approach the desk to a more customer-centered, librarian-efficient two component model. General reference questions and other standard user services are provided by highly trained library staff members from various departments throughout the library. In contrast, reference librarians are only called to assist library users when the need is indicated either by complexity of a question or when library users specifically request the services of a librarian. The results so far have been positive and usage statistics have increased each month. The Woodruff Library hopes to enhance services and efficiency as we move forward. The new service delivery model has enhanced our library's ability to achieve its mission of providing the highest level of service to library users in the Atlanta University Center community. 


\section{REFERENCES}

Arendt, Julie, and Mary K. Taylor. 2006. When the walls crash down: Offer services where the students are. College \& Research Libraries News 67: 698-700.

Carlson, Scott. 2007. Are reference desks dying out? Chronicle of Higher Education 53: A37.

Cook, Hope M. 2006. The emerging technology: $21^{\text {st }}$ Century web based environments and their resultant effect on the work responsibilities of academic reference librarians-were the predictions correct. Electronic Journal of Academic and Special Librarianship 7 no.2 (Summer), http://southernlibrarianship.icaap.org/ content/v07n02/cook_h01.htm (accessed February 4, 2007).

Fritch, John W., and Scott B. Mandernack. 2001. The emerging reference paradigm: A vision of reference services in a complex information environment. Library Trends 50: 286-305.

Harrelson, Larry E. 1974. Large libraries and information desks. College $\varepsilon$ Research Libraries 35: 21-27.

Harter, Jennifer. 2006. The development of a combined service desk in Hayden Library, Columbia Reference Services Symposium. <https://www1.columbia.edu/ $\mathrm{sec} / \mathrm{cu} /$ libraries/bts/img/assets/8521/harter.ppt> (accessed February 4, 2007).

Kleiner, Jane P. 1968. The information desk: The library's gateway to service. College $\varepsilon$ Research Libraries 29: 496-501.

Lipow, Anne G. 2003. The future of reference services papers: Point-of-need reference service: No longer an afterthought. Reference Services Review 31, no.1, http:// www.ingentaconnect.com/content/mcb/240/2003/00000031/00000001/art00007 (accessed January 31, 2007).

Massey-Burzio, Virginia. 1998. From the other side of the reference desk: A focus group study. The Journal of Academic Librarianship 24, no. 3, http://search. ebscohost.com/login.aspx?direct $=$ true $\& \mathrm{db}=\mathrm{a} 9 \mathrm{~h} \& \mathrm{AN}=805686 \&$ site $=$ ehost-live (accessed February 4, 2007).

Massey-Burzio, Virginia. 1992. Reference encounter of a different kind: A symposium. Journal of Academic Librarianship 18, no. 5 (November), <http://search. ebscohost.com/login.aspx?direct=true $\& \mathrm{db}=\mathrm{a} 9 \mathrm{~h} \& \mathrm{AN}=9705181654 \&$ site $=$ ehost-live $>$ (accessed February 4, 2007).

Mosley, Pixey Anne. 2007. Assessing user interactions at the desk nearest the front door. Reference \& User Services Quarterly 47: 159-167.

Radcliff, Carolyn J. 1998. Issues for information desks in academic libraries: A case study. Journal of Interlibrary Loan, Document Delivery \& Information Supply 9: 57-66.

Sonntag, Gabriela, and Felicia Palsson. 2007. No longer the sacred cow - No longer a reference desk: Transforming reference service to meet $21^{\text {st }}$ century user needs. Library Philosophy and Practice, <http://vnweb.hwwilsonweb.com/hww/ jumpstart.jhtml?recid=0bc05f7a67b1790e8daabea77738dd7c56ab6009fe39123f5f3d 2295de9fe598e446b6ea03be5c061\&fmt=C> (accessed February 4, 2008).

Whitson, William. 1995. Differentiated service: A new reference model. Journal of Academic Librarianship 21: 103-110.

Wong, Sandra, and Andrea O'Shea. 2004. Librarians have left the building: Ask us HERE! At Simon Fraser University. Feliciter 50, no. 3, <http://search.ebscohost. $\mathrm{com} /$ login. aspx?direct $=$ true $\& \mathrm{db}=\mathrm{a} 9 \mathrm{~h} \& \mathrm{AN}=13913151 \&$ site $=$ ehost-live $>$ (accessed January 31, 2007). 